\title{
MOTIVASI PENYALAHGUNAAN LEM PEREKAT YANG MENGANDUNG LYSERGIC ACID DIETHYLAMIDE PADA REMAJA MENURUT KAJIAN MODEL SISTEM PERILAKU JOHNSON
}

\author{
Rahel A. Kululu \\ Esrom Kanine \\ Andi Buanasari \\ Program Studi Ilmu Keperawatan Fakultas Kedokteran \\ Universitas Sam Ratulangi \\ Email :rahelabigael12@gmail.com
}

\begin{abstract}
Abstrack: The use of narcotics, psychotropic and other addictive substances hasbeen used up to adolescents. Adolescents use drugs because it has many motivation, motivation arising from within themselves as well as the motivation that arise because of the encouragement from the outside.The use of this drug can also be seen in Johnson's behavioral system model by reviewing with seven subsystems. The purpose of this study is to determine the motivation of ehabon abuse in adolescents according to Johnson's behavioral system model.This research method using cross sectional design. The sampling technique used purposive sampling with a sample of 83 respondents. Methods of data collection using questionnaires of motivation and questionnaire Johnson behavioral system model.The result of Chi-square test results obtained significantly smaller than the value of 0.05 in the subsystem affilative $p=$ 0.027, dependency subsystem $p=0.000$, subsystem eliminative $p=0.006$ and the aggressive subsystem $p=0.032$. Conclusion of the results of this study indicate that there is a relationship motivation abuse of adhesive glue which contains lysergic acid diethylamidein adolescents according to Johnson's behavioral system model in the affiliative subsystem, dependency, eliminative and aggressive.
\end{abstract}

Keywords:Drug abuse, motivation, adolescents

Abstrak: Penggunaan narkotika, psikotropika dan zat adiktif lainnya sudah digunakan sampai dikalangan remaja. Remaja menggunakan napza karena memiliki berbagai motivasi baik motivasi yang timbul dari dalam diri sendiri maupun motivasi yang timbul karena adanya dorongan dari luar. Penggunaan napza ini juga dapat dilihat dalam sistem perilaku Johnson dengan mengkaji berdasarkan 7 subsistem Tujuan penelitian ini adalah untuk mengetahui motivasi penyalahgunaan ehabon pada remaja menurut kajian model sistem perilaku Johnson. Metode penelitian ini menggunakan desain penelitian cross sectional. Teknik pengambilan sampel menggunakan teknik purposive sampling dengan jumlah sampel 83 responden. Metode pengumpulan data penelitian menggunakan kuesioner motivasi dan kuesioner kajian model sistem perilaku Johnson. Hasil uji chi-square didapatkan lebih kecil dari nilai signifikan 0,05 pada subsistem afilatif $p=0,027$, subsistem ketergantungan $p=0,000$, subsistem eliminatif $p=0,006$ dan pada subsistem agresif $p=0,032$. Kesimpulan hasil penelitian ini menunjukkan bahwa terdapat hubungan motivasi penyalahgunaan lem perekat yang mengandung lysergic acid diethylamide pada remaja menurut kajian model sistem perilaku Johnson pada subsistem afiliatif, ketergantungan, eliminatif dan agresif.

Kata kunci :Penyalahgunaan napza, motivasi, remaja 


\section{PENDAHULUAN}

Penyalahgunaan

narkotika, psikotropika dan zat adiktif lainnya sudah menjadi masalah yang besar untuk setiap bangsa diseluruh dunia saat ini dan juga bukan hanya jadi permasalahan suatu bangsa diseluruh dunia bahkan menjadi masalah global. Napza sendiri mudah didapat dan seseorang yang menggunakannya akan merasa kecanduan. Penyalahgunaan napza khususnya di Indonesia digunakan oleh semua kalangan dan strata termasuk golongan usia remaja (Amanda dkk, 2017). Menurut Pusat Penelitian Data Dan Informasi Badan Narkotika Nasional (2017) dalam setahun terakhir penyalahgunaan narkotika psikotropika dan zat adiktif lainnya terdapat 3.376.115 pengguna di seluruh Indonesia dan Sulawesi Utara sendiri pada tahun 2017 berada pada peringkat ke 24 dari 34 Provinsi dengan jumlah penyalahgunaan napza sebanyak 30.646 pengguna dengan usia 10-59 tahun. Di Manado sendiri dari tahun 2015 hingga bulan Oktober 2018 terdapat 534 penyalahgunaan napza $85 \%$ dari total tersebut atau setara dengan 454 penyalahgunaan tersebut adalah pelajar dan remaja dengan pengguna napza jenis lem perekat yang berada di Kecamatan Singkil berjumlah 105 orang (BNN Kota Manado, 2018).

Korban dari penyalahgunaan narkotika, psikotropika dan zat adiktif lainnya terdapat pada remaja yang masih duduk dibangku sekolah. Menurut BNN Kota Manado (2018) sendiri remaja yang menyalahgunakan napza terdapat 454 orang dan sedangkan di Manado pada tahun 2017 hingga bulan Oktober 2018 terdapat 208 penyalahgunaan napza yang direhabilitasi dan hampir $85 \%$ atau sekitar 177 penyalahgunaan napza yang direhabilitasi adalah remaja. Remaja dapat terlibat dalam penyalahgunaan napza karena masa remaja adalah masa dimana seseorang mencari jati diri, memasuki masa yang labil serta memiliki keinginan yang besar untuk mencoba sesuatu dan mudah terpengaruh oleh lingkungan sekitar (Nurmaya, 2016). Terdapat berbagai penyebab seorang remaja menyalahgunakan napza diantaranya adalah terpengaruh dalam komunitas, stress, bosan, perasaan ingin mencoba hal yang baru, menyukai sensasi mabuk, memiliki masalah keluarga (Chomariah, 2015).

Remaja yang menggunakan napza memiliki berbagai motivasi. Motivasi ini terbagi dua yaitu motivasi intrinsik dan motivasi ekstrinsik, dimana motivasi intrinsik adalah motivasi yang timbul dari dalam diri seseorang sedangkan motivasi ekstrinsik yaitu motivasi yang muncul karena ada dorongan dari luar yang dapat mempengaruhi orang tersebut (Aridhona dkk, 2017). Motivasi remajadalam penyalahgunaan napza yaitu karena pola pergaulan, gaya berteman, keluarga dengan broken home, rasa ingin tau yang tinggi, ingin menghilangkan stress yang dirasakanserta memiliki masalah bersama orang tua (Amanda dkk, 2017).

$$
\text { Motivasi remaja juga }
$$

menyalahgunakan narkotika psikotropika dan zat adiktif lainnya menurut kajian sistem perilaku Johnson menyebutkan bahwa terdapat tujuh subsistem dalam sistem perilaku Johnson dan setiap respon dari subsistem memiliki motivasi yang di pengaruhi oleh faktor biologi, psikologi dan sosial. Penelitian ini dilakukan untuk mengetahui motivasi remaja menyalahgunakan napza dengan melakukan pengkajian berdasarkan sistem perilaku Johnson (Alligood \& Tomey, 2006).

\section{METODE PENELITIAN}

Penelitian initermasuk dalam jenis penelitian kuantitatif dengan menganalisis gambaran hubungan antara kedua variabel yaitu variabel independen (Motivasi penyalahgunaan lem perekat yang mengandung lysergic acid diethylamide) dan variabel dependen (Kajian model sistem perilaku Johnson). Penelitian ini menggunakandesain penelitian cross 
sectional. Penelitian ini dilaksanakan diKecamatan Singkil pada bulanDesember 2018.Populasi penelitian ini adalah remaja yang menyalahgunakan lem perekat dengan jumlah 105 remaja. Pengambilan sampel menggunakan teknik purposive sampling dengan rumus slovin maka didapatkan jumlah sampel minimal 83 remaja. Instrumen penelitian yang digunakan yaitu kuesionermotivasi penyalahgunaan lem perekatyang mengandung lysergic acid diethylamide yang telah diuji validitasnya. Kuesioner ini terdiri dari 8pertanyaan dengan pilihan $1=$ benar, $0=$ salah. Setelah lembar kuesioner diisi oleh responden, kemudian dilakukan penghitungan skor dengan cara menjumlahkan skor. Untuk menentukan motivasipada remaja adalah motivasi baik $<4$ dan motivasi buruk $\geq 4$ (Harvey, 2015)

Pengukuran kajian model sistem perilaku Johnson menggunakan kuesioner dengan kriteria skor $1=$ tidak pernah sesuai, $2=$ kadang-kadang, $3=$ sering, $4=$ selalu. Cara penilaiannyaskor $\leq 12.5-5$ perilaku adaptif dan perilaku maladaptif jika skor > 12.5-20 dilihat berdasarkan subsistem(Alligood \& Tomey, 2006). Pengolahan data yang diperoleh dari hasil penelitian ini diolah secara manual dengan mengelompokkan hasil wawancara dan observasi kemudian dilakukan penghitungan skor dan dianalisis menggunakan uji statistik melalui sistem komuterisasi dengan beberapa tahap yaitu editing, coding, entering, cleaning (Notoatmodjo, 2012). Analisa bivariat dalam penelitian ini yaitu untuk mengetahui hubungan motivasi penyalahgunaan lem perekat yang mengandung lysergic acid diethylamide pada remaja menurut kajian model sistem perilaku Johnson. Peneliti menggunakan uji statistik Chi Squaredengan tingkat kemaknaan 95\% $(\alpha=0,05)$.
HASIL dan PEMBAHASAN

1. Karakteristik Responden

Tabel 1. Distribusi Responden

Berdasarkan Umur

\begin{tabular}{cccccc}
\hline \multicolumn{5}{c}{ Umur } \\
\hline $\mathbf{n}$ & $\%$ & Mean & Median & $\begin{array}{c}\text { Min - } \\
\text { Max }\end{array}$ & SD \\
\hline 83 & 100 & 15,03 & 15 & $11-18$ & 1,565 \\
\hline
\end{tabular}

Sumber : Data Primer 2019

Berdasarkan rentang umur responden mayoritas adalah 15 tahun.Usia ini remaja memiliki rasa keingintahuan yang besar, menyukai petualangan dan tantangan serta cenderung berani mengambil resiko atas perbuatannya tanpa didahului oleh pertimbangan yang matang dan dapat melakukan beberapa kenakalan. Menurut Amanda dkk (2017) ada beberapa kenakalan yang dilakukan remaja diantaranya adalah kenakalan khusus seperti penyalahgunaan napza.

Tabel 2.Distribusi Responden Berdasarkan Jenis Kelamin

\begin{tabular}{ccc}
\hline Jenis Kelamin & n & \% \\
\hline Laki-laki & 59 & 71,1 \\
Perempuan & 24 & 28,9 \\
\hline Total & $\mathbf{8 3}$ & $\mathbf{1 0 0}$ \\
\hline
\end{tabular}

Sumber : Data Primer 2019

Tabel 2 dari hasil penelitian menunjukkan bahwa mayoritas responden memiliki jenis kelamin laki-laki(71,1\%).Hasil penelitian Riyadi (2015) menyatakan bahwa remaja laki-laki lebih ambisius dan memiliki tingkat agresi yang lebih tinggi dibandingkan dengan remaja perempuan. Penelitian ini juga sejalan dengan Andaryani (2013) juga mengatakan bahwa terdapat perbedaan antara laki-laki dan perempuan dimana laki-laki memiliki tingkat self control yang lebih rendah dibandingkan dengan perempuan sehingga banyak ditemukan laki-laki lebih cenderung melakukan tindakan negatif dan menyimpang misalkan penyalahgunaan obat-obatan, alkohol dan pencurian dibandingkan dengan perempuan. 
Tabel 3. Distribusi Responden Berdasarkan Pendidikan

\begin{tabular}{ccc}
\hline Pendidikan & n & \% \\
\hline SD & 1 & 1,2 \\
SMP & 40 & 48,2 \\
SMA & 33 & 39,8 \\
SMK & 9 & 10,8 \\
\hline Total & $\mathbf{8 3}$ & $\mathbf{1 0 0}$ \\
\hline
\end{tabular}

Sumber : Data Primer 2019

Hasil analisadari tabel 3 menunjukkan mayoritas responden masih dalam taraf SMP (48,2\%). Mayoritas remaja pengguna napza pada penelitian ini masih berada pada taraf sekolah menengah pertama yang ada pada rentang usia rentang 12-15 tahun. Pada masa ini remaja akan membentuk kelompok dalam pergaulan dengan teman sebayanya (peer group) (Wendari dkk, 2016). Pada taraf ini, remaja berada pada masa pubertas, penuh energi, serba ingin tahu, mudah terpengaruh, nekat, berani, emosi tinggi, selalu ingin mencoba dan tidak mau ketinggalan (Tamrin dkk, 2013).

\section{Analisa Univariat}

Tabel 4.Distribusi Responden Berdasarkan Motivasi

\begin{tabular}{ccc}
\hline Motivasi & n & \% \\
\hline Baik & 21 & 25,3 \\
Buruk & 62 & 74,7 \\
\hline Total & $\mathbf{8 3}$ & $\mathbf{1 0 0}$ \\
\hline
\end{tabular}

Sumber : Data Primer 2019

Tabel 4 menunjukkan bahwa mayoritas responden memiliki motivasi buruk (70,4\%) Hasil penelitian Tamrin dkk (2013) diketahui bahwa motivasi remaja menggunakan napza jenis lem perekat diantaranya adalah karena hanya ingin coba-coba dan hanya ikut-ikutan. Hal demikian didukung oleh hasil penelitian Chomariah (2015) bahwa remaja yang menggunakan napza jenis lem perekat hanya terbawa dengan kondisi lingkungan teman sekitar karena sering bergaul dengan komunitas yang ada dan awalnya hanya untuk coba-coba.
Tabel 5.Distribusi Responden Berdasarkan Kajian Model Sistem Perilaku Johnson

\begin{tabular}{lcccc}
\hline \multicolumn{1}{c}{ Subsistem } & Adaptif & $\%$ & $\begin{array}{c}\text { Malad } \\
\text { aptif }\end{array}$ & $\%$ \\
\hline Afiliatif & 29 & 34,9 & 54 & 65,1 \\
Ketergantungan & 26 & 31,3 & 57 & 68,7 \\
Ingestif & 37 & 44,6 & 46 & 55,4 \\
Eliminatif & 36 & 43,4 & 47 & 56,6 \\
Seksual & 49 & 59,0 & 34 & 41,0 \\
Prestasi & 32 & 38,6 & 51 & 61,4 \\
Agresif & 33 & 39,8 & 50 & 60,2 \\
\hline
\end{tabular}

Sumber : Data Primer 2019

Berdasarkan tabel 5 menunjukkan bahwa pada subsistem afiliatif memiliki perilaku yang maladaptif 54 remaja $(65,1 \%)$. Subsistem ini membahas dimana remaja yang berada dalam sebuah komunitas, yang dapat terpengaruh oleh bujukkan yang ditawarkan dari komunitas tersebut. Peneliti berasumsir remaja memiliki perilaku yang maladaptif karena emaja yang diteliti pada penelitian ini terpengaruh serta sering berada dalam sebuah komunitas dimana komunitas tersebut sering menggunakan lem perekat. Hasil penelitian Horman dkk (2018) menyatakan dimana remaja menjadi ketagihan dalam menggunakan napza jenis lem perekat karena terpengaruh teman sepermainan atau komunitas yang ada.

Hasil penelitian untuk subsistem ketergantungan memiliki perilaku yang maladaptif dengan jumlah 54 remaja (65,1\%). Disubsistem inimembahas tentang dimana seorang remaja ingin mempromosikan diri atau pamer, ingin diakui dan diterima oleh komunitas yang ada. Peniliti berasumsi bahwa remaja memiliki perilaku yang maladaptif pada penelitian ini karena remaja tidak mau ketinggalan trend yang ada pada komunitas mereka dan remaja tersebut ingin diakui pada komunitasnya. Menurut Amanda dkk (2017) dimana pada penelitian ini mengatakan bahwa remaja menggunakan napza jenis lem perekat ingin terlihat lebih keren, percaya diri.

Subsistem ingestif memiliki perilaku yang maladaptif 46 remaja $(55,4 \%)$. Dalam subsistem ini membahas 
tentang kepuasan nafsu makan seseorang. Peneliti berasumsi, remaja memiliki perilaku yang maladaptif karena remaja pada penelitian ini sering merasa sulit untuk makan, nyeri pada bagian perut dan sering merasa mual hingga muntah. Sofiyah (2009) menyatakan bahwa seseorang yang menggunakan napza akan mengalami penurunan fungsi makan mual serta muntah sehingga dapat menyebabkan radang lambung.

Hasil penelitian ini menunjukkan dalam subsistem eliminatif remaja ada pada perilaku yang maladaptif 47 remaja $(56,6 \%)$. Proses eliminatif tubuh yang dibahas pada subsistem ini. Peneliti berasumsi, remaja memiliki perilaku yang maladaptif karena remaja pada penelitian ini merasa terjadi gangguan pada saat buang air besar dan buang air kecil kemudian remaja tersebut sering merasa cepat lelah dan sering merasa sakit pada bagian kanan atas perut karena menggunakan napza jenis lem perekat tersebut. Hasil penelitian ini didukung dengan penelitian yang dilakukan Anggreni (2015) menyatakan bahwa remaja akan mengalami gangguan pada hati dan ginjal, dimana hati akan terjadi gangguan menetralisir racun serta pada ginjal akan terjadi gangguan pada penyaringan zat-zat yang tidak berguna dalam tubuh.

Mayoritas remaja dalam subsistem seksual memiliki perilaku yang adaptif 49 remaja $(59,0 \%)$. Dalam subsistem ini membahas tentang penyakit yang terjadi pada remaja laki-laki dan perempuan. Peneliti berasumsi bahwa remaja memiliki perilaku yang adaptif karena pada penelitian ini, remaja laki-laki maupun remaja perempuan belum merasakan penyakit-penyakit yang terjadi pada subsistem ini. Hasil penelitian ini tidak sejalan dengan penelitian yang dilakukan Sofiyah (2009) menyatakan bahwa penyakit yang akan dirasakanpada laki-laki diantaranya adalah penyusutan testis, penurunan libido sedangkan pada perempuan dapat menyebabkan keguguran, kelahiran prematur, menstruasi tidak teratur serta amenorhe.

Penelitian dalam subsistem prestasi remaja memiliki perilaku yang maladaptif terdapat 51 orang $(61,4 \%)$. Pada subsistem ini membahas tentang bagaimana seorang remaja dalam beradaptasi disekolah ketika mereka telah menggunakan napza jenis lem perekat ini. Peneliti berasumsi bahwa remaja memiliki perilaku yang maladaptif karena remaja pada penelitian ini ketika mereka disekolah, mereka merasa kesulitan untuk berkosentrasi dalam belajar dan mereka kesekolah hanya karena keterpaksaan dari orang tua. Penelitian ini sejalan dengan penelitian yang dilakukan oleh Nurmaya (2016) menyatakan bahwa seorang yang menggunakan napza akan mengalami kemalasan dalam ruang lingkup sekolah serta sulit untuk berkosentrasi ketika berada dalam lingkungan sekolah.

Subsistem agresif remaja memiliki perilaku yang maladaptif 50 remaja $(60,2 \%)$. Subsistem ini remaja akan bisa menyakiti orang lain dan masyarakat ingin dilindungi serta dihormati untuk preoperti mereka. Peneliti berasumsi, remaja memiliki perilaku yang maladaptif karena remaja pada penelitian ini menyakiti orang lain dengan cara memaki, kemudian bisa membalas ketika seseorang memukulnya dan dapat merusak properti orang lain ketika remaja tersebut berkelahi. Hasil penelitian ini sejalan dengan penelitian yang dilakukan Chomariah (2016) menyatakan bahwa perilaku remaja penghisap lem yang dapat mereka lakukan ternyata berdampak pada sebuah kriminalitas seperti mencuri, berkelahi serta memalak orang lain. 
Tabel 6. Hubungan motivasi penyalahgunaan lem perekat yang mengandung lysergic acid diethylamide pada remaja menurut kajian model sistem perilaku Johnson

\begin{tabular}{lccc}
\hline \multicolumn{1}{c}{ Variabel } & \multicolumn{2}{c}{ Motivasi } & Hasil Uji \\
& Baik & Buruk & Chi-Square \\
\hline Afilatif & & & \\
Adaptif & 12 & 17 & $p=0,027$ \\
Maladaptif & 9 & 45 & \\
\hline Ketergantungan & & \\
Adaptif & 15 & 11 & $p=0,000$ \\
Maladaptif & 6 & 51 & \\
\hline Ingestif & & & \\
Adaptif & 10 & 27 & $p=0,944$ \\
Maladaptif & 11 & 35 & \\
\hline Eliminatif & & & \\
Adaptif & 15 & 21 & $p=0,006$ \\
Maladaptif & 6 & 41 & \\
\hline Seksual & & & \\
Adaptif & 13 & 36 & $p=0,958$ \\
Maladaptif & 8 & 26 & \\
\hline Prestasi & & & \\
Adaptif & 10 & 22 & $p=0,467$ \\
Maladaptif & 11 & 40 & \\
\hline Agresif & & & \\
Adaptif & 13 & 22 & \\
Maladaptif & 8 & 42 & \\
\hline Sumber : & & & \\
\hline
\end{tabular}

Sumber : Data Primer 2019

Tabel 6 menunjukkan bahwa hubunganmotivasi dengan subsistem afiliatif diperoleh hasil uji Chi Square p value $=0,027$ maka dapat disimpulkan ada hubungan motivasi penyalahgunaan lem perekat yang mengandung lysergic acid diethylamide dengan subsistem perilaku afiliatif. Peneliti berasumsi bahwa motivasi sebagian remaja menggunakan lem perekat yang mengandung lysergic acid diethylamide karena faktor mereka berada dalam sebuah komunitas dimana komunitas tersebut menawarkan untuk menggunakan lem perekat. Sebanyak $72 \%$ faktor pergaulan memiliki pengaruh yang besar dalam seseorang menggunakan napza dengan berbagai alasan diantaranya adalah ingin mencoba sesuatu yang baru (Kholik dkk, 2014)

Analisa hubungan motivasi dengan subsistem ketergantungan dengan menggunakan uji Chi Squaredidapatkan p value $=0,000$ hal ini menunjukkan ada hubungan motivasi penyalahgunaan lem perekat yang mengandung lysergic acid diethylamide dengan subsistem ketergantungan. Remaja merupakan seseorang yang ingin dianggap hebat dan pemberani ketika menggunakan napza (Partodiharjo, 2010). Peneliti berasumsi, motivasi remaja dalam penelitian ini menggunakan lem perekat tersebut karena mereka kurang merasa percaya diri, ingin pamer, ingin diakui dalam komunitas mereka, dibilang tidak gaul, tidak ingin kehilangan teman dan ingin memiliki teman yang banyak. Penelitian sebelumnya Tamrin dkk (2013) menunjukkan dimana temannya yang berada dalam komunitas yang sama mengatakan tidak gaul kalau tidak mencoba sesuatu yang baru sehingga remaja tersebut mencoba menggunakannya.

Penelitian antara motivasi dengan subsistem ingestif didapatkan hasil $\mathrm{p}$ value $=0,944$ sehingga kesimpulannya tidak ada hubungan motivasi penyalahgunaan lem perekat yang mengandung lysergic acid diethylamide dengan subsistem ingestif. Hasil penelitian Masjid (2017) mengatakan bahwa remaja yang menggunakan napza matanya akan terlihat cekung dan merah, sakit kepala serta sembelit dan sakit perut tanpa alasan yang jelas namun dari hasil penelitian yang dilakukan peneliti berasumsi bahwa remaja yang menggunakan napza jenis lem perekat menunjukkan dalam proses makan masih seperti biasa tetapi ada remaja pengguna napza jenis lem perekat ini merasa sulit untuk makan dan sering mual serta muntah.

Crosstab mengenai motivasi dengan subsistem eliminatif diperoleh $\mathrm{p}$ value $=0,006<0,05$ sehingga hal ini menunjukkan ada hubungan motivasi penyalahgunaan lem perekat yang mengandung lysergic acid diethylamide dengan subsistem eliminatif. Remaja pada penelitian ini ketika dilihat dari hasil kuesioner didapatkan bahwa motivasi 
remaja ini awalnya hanya coba-coba dan banyak hanya terpengaruh teman namun remaja tersebut tidak tahu akan terjadi perubahan dalam proses eliminatif pada remaja yang menggunakan lem perekat ini. Remaja yang telah menggunakan napza jenis lem perekat ini telah terjadi perubahan buang air kecil, merasa cepat lelah, sesak napas bahkan ada remaja yang kulitnya berubah menjadi sedikit kuning. Hasil penelitian ini sejalan dengan penelitian sebelumnya oleh Hasni (2018) bahwa remaja yang menggunakan napza akan merasa sakit kepala, mual-mual bahkan sesak napas.

Analisa hubungan antara motivasi dengan subsistem seksual dengan menggunakan uji Chi Square p value = 0,958 dan dapat disimpulkan bahwa tidak ada hubungan motivasi penyalahgunaan lem perekat yang mengandung lysergic acid diethylamide dengan subsistem seksual. Dalam tubuh manusia memiliki hormon dopamin dimana hormon ini dapat memberikan kebahagiaan serta mempengaruhi perilaku seseorang namun jika hal tersebut berlangsung pada pengguna napza bisa berbahaya karena dapat menyebabkan adiksi. Adiksi merupakan suatu kondisi ketergantungan fisik dan mental yang ada pada diri penyalahgunaan napza untuk dapat menggunakannya seacara terus menerus yang akan mengakibatkan beberapa gangguan dalam fisiologis seseorang tetapi pada penelitian ini dalam subsistem seksual baik pria maupun wanita tidak mengalami perubahan dan remaja tersebut belum merasakan dampaknya. Hal ini tidak sejalan dengan penelitian yang dilakukan oleh Aggreni (2015) dimana seseorang yang telah menggunakan napza akan terjadi perubahan periode menstruasi, ketidakaturan menstruasi dan amenorhe pada wanita sedangkan pada pria akan mengalami kemandulan serta penyusutan testikel

Hasil analisa hubungan motivasi dengan subsistem prestasi didapatkan hasil uji Chi Square p value $=0,467$ dan dapat disimpulkan bahwa tidak ada hubungan motivasi penyalahgunaan lem perekat yang mengandung lysergic acid diethylamidedengan subsistem prestasi. Penggunaan napza dapat mengalami kerusakan pada sel-sel otak, syaraf, pembuluh darah, darah dan seluruh jaringan pada tubuh manusia namun hasil penelitian yang telah dilakukan pada subsistem ini menunjukkan bahwa remaja belum bisa merasakan efek dari penggunaan lem perekat ini (Elkindi, 2016). Penelitian yang telah dilakukan ini menunjukkan bahwa, peneliti berasumsi remaja ini masih sering ke sekolah, masih suka belajar namun ada beberapa remaja pengguna napza jenis lem perekat ini kadang motivasi pergi kesekolah hanya karena keterpaksaaan dari orang tua yang akhirnya tidak bisa berkosentrasi dalam belajar yang kemudian remaja ini melakukan bolos sekolah. Hal ini sejalan dengan penelitian yang dilakukan sebelumnya oleh Nurlila \& La Fua (2017) bahwa ketika seorang remaja sudah mencoba untuk menggunakan napza maka remaja tersebut akan terganggu fungsi otak, sopan santun hilang, motivasi untuk sekolah menurun, sering mengantuk dikelas, sering membolos serta tidak disiplin dalam lingkungan sekolah.

Crosstab dengan menggunakan uji Chi Square dari motivasi dengan subsistem agresif diperoleh $\mathrm{p}$ value $=0,032<0,05$ sehingga hal ini menunjukkan ada hubungan motivasi penyalahgunaan lem perekat yang mengandung lysergic acid diethylamide dengan subsistem agresif. Perilaku agresif adalah perilaku yang dapat menyakiti atau merusak barang dari orang lain dan adiksi terhadap napza bukan hanya berdampak pada fisik dan mental seseorang namun berdampak juga pada emosional dan spiritual (Amir dkk, 2007). Hasil penelitian yang didapatkan bahwa kadang remaja melakukan perilaku mencuri untuk mendapatkan uang, dapat berkelahi dengan temannya yang berada dalam komunitas yang sama dikarenakan hanya hal kecil, misalnya tidak bisa bantu 
untuk menambahi sedikit uang yang dimilikinya untuk membeli 1 kaleng lem kemudian kadang mereka bisa berkelahi hingga melemparkan barang yang ada didekatnnya. Hal ini sejalan dengan penelitian yang dilakukan oleh Chomariah (2017) dimana seorang anak yang awalnya hanya kebiasaan menggunakan lem dan selanjutnya sikapnya berubah, kalau remaja tersebut membutuhkan uang namun remaja tersebut tidak memilikinya, remaja itu akan melakukan tindakan mencuri untuk mendapatkan uang yang ada.

\section{SIMPULAN}

Motivasi penyalahgunaan lem perekat yang mengandung lysergic acid diethylamide pada remaja menurut kajian model sistem perilaku Johnson dalam penelitian ini dapat disimpulkan bahwa remaja memiliki perilaku yang buruk dan memiliki berbagai motivasi ketika menggunakan napza jenis lem perekat yang mengandung lysergic acid diethylamide serta dapat mempengaruhi beberapa subsistem dalam sistem perilaku Johnson diantaranya adalah subsistem afiliatif, subsistem ketergantungan, subsistem eliminatif dan subsistem agresif.

\section{DAFTAR PUSTAKA}

Alligood, M. R \& Tomey, A. M. (2006). Nursing Theorist and their work 6th $E d$. ST. Louis: Mosby Elsevier, Inc

Amanda, M. P, Humaedi, S \& Santoso, M. B. (2017). Penyalahgunaan Narkoba Di Kalangan Remaja (Adolescent Substance Abuse). Volume 4, Nomor 2, 2442-448X. JurnalOnline Universitas Padjadjaran Bandung.

Amir, M, Ali, P \& Duse I. (2007). Narkoba Ancaman Generasi Muda. Jakarta: Pustaka Timur

Andaryani, D. (2013). Perbedaan Tingkat Self Control Pada Remaja LakiLaki Dan Remaja Perempuan Yang
Kecanduan Internet.Jurnal Online Universitas Airlangga

Anggreni, D. (2015). Dampak Bagi Pengguna Narkotika, Psikotropika, Dan Zat Adiktif (NAPZA) Di Kelurahan Gunung Kelua Samarinda ULU. Volume 3, Nomor 3. Jurnal Online Sosiatri-Sosiologi.

Aridhona, J. Barmawi \& Junia, N. (2017). Hubungan Antara Dukungan Sosial Dengan Motivasi Pasca Kesembuhan Pada Remaja Penyalahgunaan Narkoba Di Banda Aceh. Jurnal Online Universitas Negeri Malang.

Badan Narkotika Nasional Republik Indonesia. (2017). Survei Hasil Penyalahgunaan NARKOBA Di 34 Provinsi Tahun 2017.

Badan Narkotika Nasional Kota Manado. (2018). Survei BNN Kota Manado, Penyalahguna Narkoba di Tingkat Pelajar Masih Tinggi.

Chomariah, S. (2015). Perilaku Menghisap Lem Pada Anak Remaja. Volume 2, Nomor 2. Jurnal Online Mahasiswa FISIP Universitas Riau.

Elkindi, H, M. (2016). Faktor Penyebab Dan Dampak Penyalahgunaan Napza. Skripsi Universitas Islam Negeri Sunan Kalijaga.

Harvey, T. (2015). Kuesioner Motivasi Merokok. Jurnal Universitas Jendreal Achmad Yani.

Hasni. (2018) Dampak Penyalahgunaan Narkoba Pada Remaja Di Desa Dongi Kecamatan Pituriawa Kabupaten Sindereng Rappang.

Horman, Y. Y, Mokalu, B \& Purwanto, A. (2018). Peran Keluarga dalam Mencegah Perilaku Menyimpang. 
e-journal Keperawatan(e-Kp) Volume 7 Nomor 1, Mei 2019

Jurnal Online Universitas Sam Ratulangi Manado.

Kholik, S, Mariana, E. R, Zainab. (2014). Faktor-Faktor Yang Mempengaruhi Penyalahgunaan Narkoba Pada Klien Rehabilitasi Narkoba Di Poli Napza RSJ Sambang Lihum. Volume 5, Nomor 1. Jurnal Online Poltekkes Banjarmasin.

Masjid, A. (2007). Awas bahaya napza. Semarang: PT Bengawan Ilmu

Nurlila, R. U \& La Fua, J. (2017). Penyalahgunaan Zat Adiktif Pada Siswa Kelas VIII Di Sekolah Menengah Pertama Negeri 05 Kota Kendari. Volume 10, Nomor 01. Jurnal Online Institut Agama Islam Negeri Kendari.

Nurmaya, A. (2016). Penyalahgunaan Napza Di Kalangan Remaja. Volume 2, Nomor 1, 2477-2518. Jurnal Psikologi Pendidikan \& Konseling.

Notoadmodjo, Soekodjo. (2012). Metodologi Penelitian Kesehatan. Edisi Revisi. Jakarta: Rineka Cipta.

Partodiharjo, S. (2010). Kenali Narkoba Dan Musuhi Penyalahgunaan. Jakarta: Esensi Erlangga Group

Riyadi, A. (2015). Risiko Penyalahgunaan Napza Pada Remaja Ditinjau Dari Jenis Kelamin, Status Tinggal Dan Status Orang Tua.

Sofiyah. (2009) Mengenal Napza dan Bahayanya. Jakarta: Be Champion Wisma Hijau

Tamrin, M, Nasir, S \& Riskiyani, S. (2013). Studi Perilaku "Ngelem" Pada Remaja DI Kec. Paleteang Kab. Pinrang. Jurnal Online Universitas Hasanuddin Makassar
Wendari, N. W, Badrujaman, B, Sismiati, A. (2016). Profil Permasalahan Siswa Sekolah Menengah Pertama (SMP) Negeri Di Kota Bogor. Jurnal Online Universitas Negeri Jakarta 